\title{
International symposium on bile pigments
}

An international symposium on bile pigments was held at the Royal Free Hospital, London, on 11 and 12 July 1966.

\section{ORIGIN OF BILE PIGMENTS}

L. G. ISRAELS (Winnipeg) produced evidence that the early labelled fraction of bilirubin which could be demonstrated using isotopically labelled glycine was composed of two components, one related to erythropoiesis and the other apparently unrelated to erythropoiesis and probably of hepatic origin.

s. SCHWARTz (Minneapolis) emphasized that the early labelled bilirubin fraction probably had many components each with its own turnover rate and that this made quantitation of each component all the more difficult.

S. H. ROBINSON (Boston) described a new experimental technique for studying the early labelled component of bilirubin in the ligated bile duct of the Gunn rat. Using ${ }^{14} \mathrm{C}$ bilirubin he measured the total miscible bilirubin pool. In addition, the rate of bile pigment formation following the administration of $2-{ }^{14} \mathrm{C}$ glycine was estimated. This allowed precise assessment of bilirubin and haem production. The early labelled peak accounted for $15 \%$ of all labelled pigment. Experiments with isolated perfused rat liver showed that the liver was a major source of the early labelled pigment.

H. N. NAKAJIMA (Tokyo) described studies of an enzyme system which could be responsible for the breakdown of haemoglobin to bilirubin.

L. POWell (London) said that the hyperbilirubinaemia in liver disease and obstructive jaundice was aggravated in most cases by a shortened red cell survival. The cause of this was unknown but studies in rats suggested the bilirubin glucuronide appeared to play a role whereas unconjugated bilirubin did not.

\section{NATURE OF BILE PIGMENTS}

R. LESTER (Boston) said that the reason why bilirubin required conjugation before excretion was probably related to its steric configuration. Studies with radioactive labelled pigments showed that mesobilirubinogen was rapidly excreted without conjugation whereas mesobilirubin, an intermediate compound resembling bilirubin in having unsaturated $\mathrm{A}$ and $\mathrm{C}$ bonds, required conjugation before excretion.

R. BRODERSEN (Copenhagen) described a radioisotope method which would detect concentrations of bilirubin diglucuronide in the serum in concentrations of $1 \mu \mathrm{g}$. per
$100 \mathrm{ml}$. In normal human adults (blood bank doners) the serum bilirubin glucuronide concentrations ranged from 5 to $25 \mu \mathrm{g}$. per $100 \mathrm{ml}$. Male donors had significantly higher serum levels than females.

B. NOIR (Buenos Aires) presented chromatographic evidence which showed that 10 to $15 \%$ of the conjugated bile pigments was present as bilirubin sulphate.

E. TALAfant (Czechoslovakia) studied the nature of ether-extractable bilirubin in obstructive jaundice caused by carcinoma. He postulated that this was a complex of bilirubin glucuronide with an unknown lipid substance.

J. D. OSTROw (Cleveland) examined the yellow pigments in bile of the Gunn rat and showed that they could not be identified with the yellow pigments formed from the photooxidative breakdown of bilirubin.

M. JIRSA (Prague) described the isolation from faeces of infants a new urobilin which was different from stercobilin, i-urobilin, and d-urobilin.

T. K. WITH (Swendborg) drew attention to the deficiencies in our knowledge of what pigments were responsible for the brown colour of normal faeces. Most textbooks attributed this to stercobilinogen but this is colourless. The other known bile pigments were unlikely to be responsible because they were either colourless or orange.

After considerable discussion it became apparent that no one in the audience knew what pigment was responsible.

\section{BILE PIGMENT TRANSPORT}

R. SCHMID (Chicago) discussed the physiological importance of the binding of bilirubin by albumin. The tightness of this bond determined the amount of bilirubin which entered the cell. Systemic acidosis and organic anions, such as salicylate and thyroxine, which compete with bilirubin for the binding sites on albumin, increased the unbound fraction of bilirubin in the plasma without altering the total body pool of bilirubin. Thus the factors responsible for bilirubin encephalopathy in the newborn were high levels of unconjugated bilirubin, low plasma albumin levels, and the metabolic acidosis which commonly exists.

G. GRODSKY (San Francisco) had studied bilirubin uptake by the hepatic cell using tritium-labelled bilirubin. These studies showed that bilirubin was taken up and concentrated as the free pigment in the rat and that this was not a rate limited process. Bilirubin in the liver was chiefly in the cell sap and was associated with a macromolecule immunologically distinct from albumin. 
L. M. GARTNER (New York) reported studies of hormonal regulation of the hepatic excretion of bilirubin. There was an hepatic excretory defect in hypophysectomized rats and this was primarily if not entirely due to decreased thyroid activity.

A. WHITE (Leeds) studied the distribution of the glucuronyl transferase of bilirubin and paranitrophenol in the cell membrane. She concluded that there was no glucuronyl transferase activity in the cytoplasmic membrane of the microsomes although this was present in both rough and smooth endoplasmic reticulum.

P. BERTHelot (Paris) discussed experiments which showed that unconjugated bilirubin could be excreted in small amounts in rat bile.

S. SCHENKER (Dallas) showed that there was a bidirectional transfer of unconjugated bilirubin via the placenta and that this was the primary route of disposal of foetal bilirubin in the monkey.

F. IBER (Baltimore) proposed a model for studying the kinetics of excretion of ${ }^{14} \mathrm{C}$ - labelled bilirubin in animals with the bile duct ligated. His analysis of the data obtained in the dog one month after common bile duct ligation indicated that there was an equilibrium between the production and disposition of bilirubin and that the disposition occured mainly in the urine with about $10 \%$ in the stool.

B. H. BILLING (London) analysed the plasma disappearance curves of conjugated and unconjugated ${ }^{14} \mathrm{C}$ bilirubin in rats with the bile duct ligated. She showed that there was no inhibition of hepatic uptake or conjugation of ${ }^{14} \mathrm{C}$ bilirubin and that renal excretion of bilirubin was the main route of its disposal.

J. de GROOTE (Louvain) had studied the renal clearance of conjugated bilirubin in 31 patients with jaundice. The bilirubin clearance was increased in obstructive jaundice as compared with parenchymatous jaundice. He postulated that this might have been due to raised plasma levels of bile salts which increase the dializability of bilirubin. In contrast E. E. OWEN (Florida) could find no significant difference in renal clearance of conjugated bilirubin in patients with different types of jaundice. He suggested that glomerular filtration was the main mechanism of renal excretion of bile pigments.

M. ALI (London) presented evidence, from studies using dialysis, infusion of substances which alter protein binding of conjugated bilirubin, and renal tubular inhibitors, that glomerular filteration was the main mechanism for bilirubin excretion in the rat.

M. FULOP (New York) discussed the possible significance of conjugated bile acids in the renal excretion of bile pigments. He suggested that bile acids acted by displacing the conjugated bilirubin from albumin, thus increasing the amount of pigment available for excretion by glomerular filtration.

M. MILNE (London) showed that the urinary excretion of urobilinogen in man was $p H$ dependent. Increased urinary urobilinogen was associated with increased production, increased absorption (as with delayed intestinal transit), with hepatobiliary disease, and with heavy alkalinization of the urine. All these factors probably played a part in causing the marked diurnal variation in urinary urobilinogen excretion. 